\title{
Umbilical Cord True Knot
}

National Cancer Institute

\section{Source}

National Cancer Institute. Umbilical Cord True Knot. NCI Thesaurus. Code C117353.

A folding of the umbilical cord in the form of a knot. 